TRANS · núm. 25.2021

MISCELÁNEA $\cdot 223-243$

LITERARIA

El presente trabajo es un estudio descriptivo que pretende, mediante la exposición de algunos casos del uso de arabismos en la traducción literaria del árabe al español, determinar la función que estos cumplen en el texto traducido. Es decir, si son los únicos equivalentes de la palabra original o hay otras alternativas más usadas, y a pesar de esto se los ha preferido para dar un matiz árabe exótico a la traducción, sobre todo cuando se trata de arabismos desusados o cuyos significados han cambiado y solo guardan semejanza fónica con la palabra árabe original.

PALABRAS CLAVE: arabismos, traducción, técnicas, equivalentes, culturemas.

\title{
El uso de arabismos en la traducción literaria del árabe al español: estudio de tres casos de narrativa contemporánea
}

\author{
Noha El Hag Hassan El Dannanah \\ Universidad de Ain Shams, El Cairo
}
The Use of Arabic Loanwords in Literary Translation from Arabic into Spanish: a study of three contemporary narrative works

This paper is a descriptive study that aims, by presenting some cases of the use of Arabisms or Arabic loanwords in the literary translation from Arabic into Spanish, to determine the function that they fulfill in the translated text. In other words, it aspires to demonstrate if they are the only equivalents of the original word in Arabic or if there are other more widely used alternatives, and, despite this, they have been preferred in the translation to give it an exotic Arabic aspect, especially when it comes to unusual or obsolete Arabic loanwords or with meanings that have changed, only keeping a phonic similarity with the original Arabic words.

KEY WORDS: arabic loanwords, translation, techniques, equivalence, culturemes. 


\section{1. INTRODUCCIÓN}

Es bien sabido que entre las lenguas siempre hay, a varios niveles, diferencias y lagunas, sean fónicas, morfológicas, sintácticas, léxico-semánticas o pragmáticas. A estas divergencias viene a añadirse también la diferencia cultural. Sin duda, son diferencias que crean vacíos a la hora de buscar equivalentes para traducir un texto de un idioma a otro. El árabe y el español, en este sentido, no son una excepción. No obstante, por causa de la larga historia de contactos entre ambas lenguas y culturas durante la época andalusí, el español se encuentra en la actualidad en una situación privilegiada por lo que atañe a la traducción, debido a la presencia en español de los arabismos, o sea, los vocablos de origen árabe, recogidos en los diccionarios de español y que son el producto de este largo contacto.

El presente estudio pretende arrojar luz sobre el recurso a voces árabes, acuñadas en el diccionario español, como técnica de traducción, y determinar si este uso es voluntario y está motivado por la preferencia del traductor, o bien obedece a imperativos del texto en razón de su tipo o la época en que se desarrolla, o más bien se usa por ser la voz más equivalente, ya sea por su carga cultural, ya porque simplemente no hay otra palabra que designe el mismo objeto. Pretende también averiguar hasta qué punto un arabismo es un buen equivalente de traducción, y si las posibles derivas semánticas o connotaciones ideológicas, que algunos arabismos han adquirido a lo largo del tiempo, hacen que su uso en la traducción resulte forzado o inadecuado.

El corpus en que se basa el presente trabajo está formado por tres novelas árabes traducidas al español. La primera es الزيني بركات (1974) del escritor egipcio Gamal El Guitani, y fue traducida al español por Milagros Nuin Monreal, quien la tituló Zaini Barakat (1994; en adelante, ZB). Trata de la vida en Egipto, concretamente en El Cairo, a comienzos del siglo xvI, y retrata diversos aspectos de la decadencia del poder mameluco en Egipto, que, al final de la novela, será reemplazado por el dominio osmanlí.

La segunda novela se titula en árabe y es obra del escritor también egipcio, Ibrahim Abdel Meguid (1996). Fue traducida al español por Pablo García Suárez con el título Nadie duerme en Alejandría (2016; en adelante, NDA). La trama de esta novela transcurre también en Egipto, durante la Segunda Guerra Mundial, y cuenta la historia de un hombre de religión, un Cheij, y su mujer, que se ven obligados a huir de su pueblo para vivir en Alejandría. La novela incide en los eventos históricos que marcaron esa época.

La tercera obra es الؤيام del escritor egipcio Taha Husein. Esta obra consta de tres partes. La primera fue publicada en 1929, y la segunda en 1939. Ambas partes fueron traducidas al español por Emilio García Gómez en 1954 con el título Los dias. Memorias de infancia y juventud (en adelante, LD). La tercera parte fue publicada en una fecha posterior a la de la traducción. Se trata de una autobiografía literaria del autor en el Egipto de la primera mitad del siglo xx. Según las palabras del propio traductor en el prólogo, esta obra «constituye un documento psicológico e histórico de primer orden».

Se han elegido estas tres novelas, que fueron escritas y traducidas en décadas diferentes y que hablan sobre épocas históricas distintas, para tratar de averiguar qué huella deja la época en la obra y estudiar tanto la elección del léxico en el texto original (en adelante, TO) como el uso de arabismos en el texto meta (en adelante, TM). Por otro lado, el hecho de que los tres autores son de la misma nacionalidad y las obras son ambientadas en Egipto, supone cierta semejanza en los vocablos utilizados en el TO, lo cual podría 
ayudar a darse una idea de los procedimientos que adoptaron los tres traductores para traducir estas voces y divisar su actitud con respecto al uso de los arabismos y cómo los emplean.

Los arabismos extraídos de las traducciones serán clasificados según el campo semántico o la temática. Se analizarán las traducciones desde una perspectiva descriptiva.

\section{MARCO TEÓRICO: LOS ARABISMOS COMO TÉCNICA DE TRADUCCIÓN}

En la traducción literaria, el traductor normalmente se enfrenta a referentes culturales o culturemas propios de la lengua original y sin equivalente exacto en la cultura meta. En el caso de la traducción del árabe al español, el uso de arabismos surge como una técnica de traducción de estos culturemas, tal como propone Rubiera Mata (2004):

En este aspecto la traducción al español tiene una ventaja añadida que salva algunos de estos problemas: los arabismos, palabras árabes que entraron en el castellano en la Edad Media y que hacen innecesaria una explicación. Hay muchos de ellos referidos a la propia religión musulmana [...]; a los vestidos [...]; y a las comidas [...] (pág. 149).

No obstante, a veces recurrir a arabismos trasciende el mero intento de colmar los vacíos culturales. Son palabras mayormente extrañas por sus referentes culturales que tienen poco que ver con la cultura española de hoy en día y que, por lo tanto, dejan un regusto exótico y un colorido local, semejante al producido por el uso del préstamo o la transliteración de las voces culturales.

Las técnicas usadas para traducir culturemas varían mucho y van desde el uso del préstamo total o adaptado de la palabra usada en la lengua de origen (LO) a la adaptación o el equivalente cultural, sustituyendo un término cultural usado en la LO por otro término cultural propio de la lengua de llegada (LT). Entre estos dos extremos se sitúan otras técnicas, como el equivalente funcional o la traducción comunicativa. Estos procedimientos determinan la tendencia del traductor a dar preferencia a la cultura original, lo que se llama, según la terminología de Venuti (1995), traducción extranjerizante, o a la cultura meta, lo que se conoce como traducción domesticante, tanto si es una decisión propia del traductor como si viene obligada por el tipo de texto o los requisitos editoriales.

Si intentamos situar el uso de los arabismos - sobre todo los poco usados o los históricos o administrativos-, en uno de estos dos grados o extremos de transposición cultural, encontraremos que no encajan exclusivamente en ninguno. La razón de ello es que los arabismos han pasado ya a ser parte del léxico español, lo que no contradice que la traducción sea domesticante, y el lector puede saber su significado, aunque sea arcaico, consultando el diccionario. Por otro lado, pueden dar a la vez un sabor exótico.

Esta es la opinión que defiende también Malika Embarek respondiendo a la pregunta de si, de contar con plena libertad de actuación, optaría por una traducción domesticante o extranjerizante. Afirmó entonces:

Desde que empecé a traducir literatura a finales de los ochenta, fui consciente de la enorme ventaja que tenemos los traductores de escritores árabes al español de contar con el tesoro de arabismos que contiene nuestra lengua.

[...] para mí, recurrir a los arabismos en la traducción de escritores francófonos representa a la vez un enorme respeto hacia el autor árabe (extranjerizar) y a la vez un retorno a casa, a al-Ándalus, de su voz expulsada (domesticar)... Siempre estoy a la caza de nuevos arabismos para poder utilizarlos en mi traducción. Así que no sé muy bien si extranjerizo o domestico... (Gutiérrez Almenara, 2016: 59). 
La traductora considera esta estrategia, que adopta al traducir a autores árabes de expresión francesa, como una estrategia de descolonización a través de los arabismos (pág. 61). Sostiene también, comentando el uso de un arabismo anticuado: «Los traductores no demasiado intrépidos no nos atrevemos a crear neologismos, pues nos reprocharían que las palabras inventadas no estén en el diccionario de la lengua. ¡Revitalicemos pues las que sí están!» (Embarek López, 2000: 16).

Sobre el uso de arabismos en las traducciones del árabe al español en la misma editorial, dice Salvador Peña:

En principio, no había buena predisposición a incluir extranjerismos. Todo lo contrario ocurría con los arabismos. Los arabismos forman parte de ese paternalismo político, como de simpatía un tanto artificial. Entonces los arabismos siempre estaban bien vistos, siempre que estuvieran en el diccionario de la Real Academia, incluso se prefería el arabismo patrimonial de hace siglos, que ha cambiado de significado y de connotaciones, a la simple transcripción del árabe (Gutiérrez Almenara, 2016: 53).

De la misma manera que hay traductores y arabistas que consideran que los arabismos, en todo caso y por más desusados que estén, son un tesoro y una fuente infalible para llenar los vacíos culturales que surgen al traducir del árabe al español, otros defienden la necesidad de buscar técnicas diferentes para no exotizar la traducción. Esto es lo que opina Gutiérrez de Terán respondiendo a la pregunta de cómo normalmente resuelve escollos tales como los extranjerismos, arabismos y referencias a la cultura de origen:

O buscando términos que reflejen el original — siempre suele haber un término que, aunque no sea un arabismo o un extranjerismo, tiene una idea muy aproximada - o intercalando explicaciones. Por ejemplo, en vez de poner «abaya», que no sé hasta qué punto estará ya incluida en el vocabulario español y que obligaría a una nota o a ponerla en cursiva, poner «una túnica negra» o algo parecido. Se pierde algo, pero también se evita el exotismo (Gutiérrez Almenara, 2016: 50).

\section{ANÁLISIS DE LOS ARABISMOS USADOS EN EL CORPUS}

\subsection{Campos temáticos de uso frecuente}

Normalmente son términos estrechamente relacionados con la cultura árabe como los términos religiosos islámicos o los administrativos y relativos a los sistemas del gobierno que fueron introducidos en la península ibérica por los habitantes de al-Ándalus. También, hay vocablos que designan las prendas tradicionales y los nombres de algunas plantas, además de aspectos de la vida social y utensilios diarios.

\subsubsection{Administración}

Se han encontrado muchas palabras relacionadas con este campo semántico en el TO de la novela Zaini Barakat debido a su temática. Ante semejantes palabras culturales, la traductora recurrió a los arabismos, que, en primer lugar, son los equivalentes acuñados que mejor reflejan el contenido semántico y referencial de las palabras culturales mencionadas; $y$, en segundo lugar, porque dan a la traducción una pátina de antigüedad y la ambientan debidamente en aquella época remota del siglo xvI, al igual que el TO. A continuación, en la Tabla 1, se ofrecen algunos ejemplos, indicando entre paréntesis el número de página en que aparecen, tanto en el TO como en el TM. 
Tabla 1

\begin{tabular}{|c|c|c|}
\hline ZB & TM & то \\
\hline 1 & El almotacén de El Cairo (14) & متولي حسبة القاهرة (7) \\
\hline 2 & El almocadén de la policía secreta de El Cairo (67) & مقدم بصاصي القاهرة (86) \\
\hline 3 & El almocadén (66) & 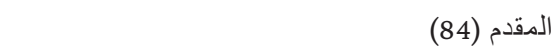 \\
\hline 4 & valí de El Cairo (148) & واليًا للقاهرة (165) \\
\hline 5 & El Gran Cadí de Egipto (124) & قاضي قضداة مصر (143) \\
\hline 6 & $\begin{array}{l}\text { Dios mediante, el Uno, Único, llegas a ser un gran cadí } \\
\text { [...] Si Dios quiere, nosotros te ayudaremos a que seas } \\
\text { juez, director de un diván... (63) }\end{array}$ & 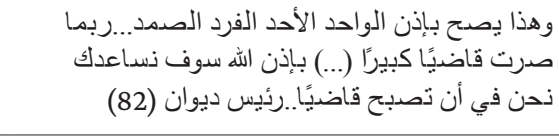 \\
\hline 7 & mamelucos (14) & المماليك (38) \\
\hline 8 & Edificio del diván que estaba al lado de la casa (44) & مبنى الديوان المجاور لدبنى البيت (65) \\
\hline 9 & $\begin{array}{l}\text { Sus baños; mercados; caravasares; sus taifas; sus } \\
\text { cantantes y los espacios de esparcimiento (45) }\end{array}$ & وأسواقها وخاناتها وطوائفها ومغنياتها وملاهيها (66) \\
\hline 10 & $\begin{array}{l}\text { los nombres de los «rumíes» residentes, de los que } \\
\text { llegan y de los que se marchan, así como los de los } \\
\text { francos de paso. (45) }\end{array}$ & والأسماء الأروام المقيمين والقادمين والراحلين \\
\hline 11 & $\begin{array}{l}\text { Hasta que se investigue su culpabilidad estará deteni- } \\
\text { do en el Aljibe de la ciudadela (35) }\end{array}$ & ترسيمه في جب القلعة حتى يتكثف أمره (57) \\
\hline
\end{tabular}

Se aprecia que se ha recurrido deliberadamente a algunos de estos arabismos que podrían haberse sustituido por palabras más usadas en el español actual. Por ejemplo, se podría traducir «jefe de la policía secreta» en vez de «almocadén» (ej. 2 y 3 ), que se usa siempre como equivalente de la palabra المقدم, sobre todo porque una de las dos acepciones acuñadas para este vocablo en el DRAE está relacionada con la milicia, y la otra está restringida a una determinada zona geográfica (Marruecos).
Otro vocablo, al parecer usado deliberadamente, es «cadi»", que se define en el DRAE como: «1. m. Entre turcos y moros, juez que entiende en las causas civiles». No obstante, se nota, a lo largo de la obra, que la traductora a veces usa este arabismo y otras veces usa la palabra de origen latino «juez» (ej. 6), y que especifica el arabismo para referirse al magistrado de alto rango, el قاضيًا كبيرا o قاضي القضاة (ej. 5).

Otros arabismos como «almotacén», «valí», «mamelucos», ... son los equivalentes culturales específicos de las voces del TO. 


\section{LD TM}

1 Encima del colchón se sentaban el muchacho cheijy sus amigos [...]. De noche, esta especie de diván se transformaba en una cama... (79)

\section{TO}

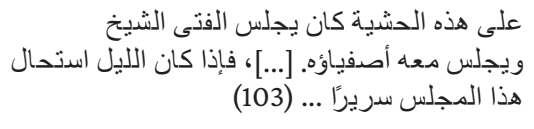

2 Leían [...] gran cantidad de divanes poéticos... (161-162)

ويقرعون دواوين الشعراء ... (205)

La palabra árabe ديوان es una voz polisémica que puede tener, entre otros, el sentido de un consejo administrativo (Tabla 1, ejemplos 6 y 8 ) y su sede o una recopilación de la poesía de un autor, y ambas acepciones las recoge el DRAE en la entrada «diván» y añade otra, cuyo origen no lo hemos encontrado en los diccionarios árabes consultados, esta es «asiento alargado, generalmente sin respaldo, para recostarse o tumbarse». Pero se deduce que toma este sentido por extensión en relación con el mobiliario de dichas salas de audiencia.

En LD, tal y como observamos en la Tabla 2, se usa este arabismo con estos dos otros significados pertenecientes a campos semánticos distintos.

En el ejemplo núm. 9 en ZB, observamos que se usa el arabismo «taifa(s)» como equivalente de la palabra árabe طوائفها, que significa «grupos o comunidades religiosas». Se usa a propósito, porque simplemente hubiera sido posible decir «grupos». Cabe mencionar que la acepción más destacada de esta palabra es la primera acepción histórica que aporta el DRAE; además, ha adquirido un nuevo significado ajeno a la voz árabe (véase la 3. a acepción):

1. f. Cada uno de los reinos en que se dividió la España musulmana al disolverse el califato cordobés. Reyes de taifa.

2. f. Bando, facción.

3. f. coloq. p.us. Reunión de personas de mala vida o poco juicio. ¡Qué taifa! ¡Vaya una taifa!
La palabra جب significa «pozo» en los diccionarios árabes, y por extensión se dio este nombre a la cárcel subterránea de la Ciudadela de Saladino en la época de los mamelucos (Ibn 'Abdillāh Al-Maghlūt, 2013: 118), y este es el referente de la palabra (en el ej.11). Notamos que la acepción de «cárcel subterránea» del arabismo «aljibe» está recogida en el DRAE, aunque se señala que está desusado (véase la acepción núm. 6). De todos modos, la traductora, por considerarlo un nombre propio, lo escribió con mayúscula inicial.

En la Tabla 3 (página siguiente), indicamos los ejemplos que hemos extraído de LD.

Se observa que el traductor de LD comparte con la traductora de ZB la misma tendencia a utilizar la voz «cadí» (ej. núm. 1), como equivalente de قاضي en vez de la alternativa «juez», aunque, efectivamente, en algún caso la ha utilizado.

En el ejemplo núm. 2, el arabismo «algara», que procede del étimo غارة gāahah, se refiere a «Tropa de a caballo que salía a correr y saquear la tierra del enemigo», según el DRAE. Este arabismo se usa en la traducción como equivalente de غزوة. Es posible que la elección de un arabismo sea deliberada para teñir el texto de antigüedad, aunque en árabe غزوة y غ غ غ (algara) no son lo mismo, sobre todo porque, según el texto, se entiende como una referencia histórica a las primeras luchas islámicas. 
Tabla 3

LD TM

1 De todos modos, era un ulema del Azhar; era el cadí canónico [...] y además residía en el Tribunal y no en la escuela. (43)
TO

$$
\text { وهو على كل حال عالم من علماء الأزهر، وهو }
$$

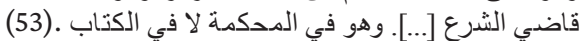

2 Lo que llevaban en sus alforjas eran, en efecto, milagros de santones, historias de conquistas y de algaras... (54)

3 La razón de todo aquello era que el joven azharista había sido elegido ese día para ser el jalifa, al que se pasea por la ciudad y por las aldeas vecinas en esa brillante festividad. (42)

$$
\begin{aligned}
& \text { كاذوا بحملون في حقائبهم مناقب الصالحين، } \\
& \text { وأخبار الفتوح والذزورات (69) }
\end{aligned}
$$

$$
\begin{aligned}
& \text { كل ذلك لأن هذا الفتى الأزهري قد اتُّذِذ في هذا }
\end{aligned}
$$

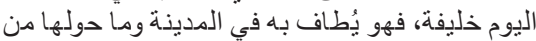

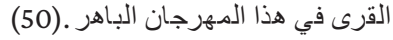

En el tercer ejemplo el arabismo jalifa está escrito en letras cursivas, aunque está en el diccionario español, incluso en el tiempo de la realización de la traducción (véase, el Mapa de diccionarios de la RAE). Esta voz es idéntica prosódicamente a su étimo خليفة (sucesor). No obstante, su acepción está restringida histórica y geográficamente en el DRAE, pues se refiere a la «autoridad del antiguo protectorado español en Marruecos»y, en Marruecos, a «lugarteniene te que sustituye a un funcionario durante sus ausencias». Según el Breve diccionario etimológico de la lengua castellana (en adelante, BDELC) de Juan Corominas (1987 [1961]): «la forma jalifa se ha tomado modernamente del árabe de Marruecos». En cambio, su alternativa «califa», que ha sufrido cambio fónico - y que probablemente fue prestada de otros idiomas europeos occidentales durante las Cruzadas, según el Diccionario de arabismos y voces afines en iberorromance de Federico Corriente-, guarda más relación con la voz del TO, pues se define en el DRAE como: «Título de los príncipes sarracenos que, como sucesores de Mahoma, ejercieron la suprema potestad religiosa y civil en algunos territorios musulmanes». Es, pues, más adecuado en el contexto.
No se han encontrado arabismos del mismo campo semántico en NDA.

\subsubsection{Religión y arquitectura islámicas}

Este campo semántico aparece a menudo en las obras árabes traducidas, debido a la recurrente referencia directa a los ritos o aspectos de la religión islámica en las obras árabes o su presencia a través de la arquitectura.

En ZB abundan los ejemplos de este campo temático, sobre todo porque en la época en la que se desarrolla la novela, la mezquita de Al-Azhar, personificada en sus ulemas, tenía una indudable autoridad popular y ejercía una gran influencia en la conciencia y la actitud de la gente de a pie. En la Tabla 4 (página siguiente), ofrecemos unos ejemplos extraídos de esta novela.

La mayoría de estos arabismos se repiten a lo largo de la novela y son los equivalentes acuñados de los términos árabes, como por ejemplo «alfaquí».

Es digno de mencionar que, consultando la herramienta Mapa de Diccionarios de la RAE, se ha observado que hasta la edición de 2001 el arabismo «hadiz» (ej. núm. 3) no estaba recogido en el DRAE, aunque lo está ahora en la actualización de 
Tabla 4

\begin{tabular}{|c|c|c|}
\hline ZB & TM & TO \\
\hline 1 & Cuando estaba sobre el almimbar de El Azhar (59) & فوق منبر الأزهر (78) \\
\hline 2 & $\begin{array}{l}\text { Un padre viejo que ansiaba la vuelta de su hijo alfaquí } \\
\text { para que dirigiera la oración en la mezquita (34) }\end{array}$ & 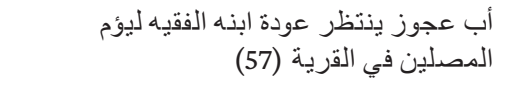 \\
\hline 3 & $\begin{array}{l}\text { Pues la conversación de Zaini estaba acompañada de } \\
\text { aleyas coránicas, del Hadiz del Profeta y de textos que } \\
\text { sólo conocían los más sabios ulemas (113) }\end{array}$ & 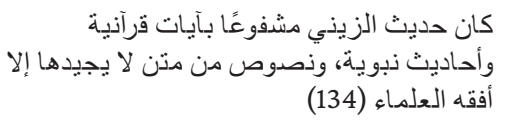 \\
\hline 4 & Mes de «xawwal» del año 912 de la hégira (23) & 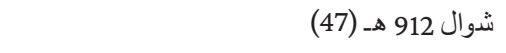 \\
\hline 5 & Se había convertido en imán de la mezquita (46) & أصبح إمادًا للمسجد (67) \\
\hline 6 & $\begin{array}{l}\text { Hasta el mihrab de la mezquita (86) } \\
\text {...y ante los mihrabes de las mezquitas (119) }\end{array}$ & في أرى محراب المسجد محراب الصدلاة (106) (139) \\
\hline 7 & Los jeques de las cofradías sufíes (43) & مشايخ الطرق (64) \\
\hline
\end{tabular}

2019 de la 23ª edición: «Del ár. ḥadīt 'relato, narración'.1. m. En la religión islámica, dicho o hecho de Mahoma de transmisión tradicional».

La palabra «imán», en el ejemplo núm. 5, se define en el DRAE en dos entradas: la primera como voz derivada del francés aimant, y la otra, como palabra procedente del árabe clásico imām. Está claro que, en este contexto, el texto se refiere a la segunda entrada, que tiene las siguientes dos acepciones:

1. m. Encargado de presidir la oración canónica musulmana, poniéndose delante de los fieles para que estos lo sigan en sus rezos y movimientos.

2. m. Guía, jefe o modelo espiritual o religioso, y a veces también político, en una sociedad musulmana.

La grafía etimológica «imam», idéntica a la pronunciación árabe, también está acuñada en el DRAE como alternativa de «imán», y fue preferida por el traductor de LD, como se verá más adelante.
En el ejemplo núm. 7, en el TO no se menciona la palabra صدوفي, pero se sobreentiende que se refiere a الطرق الصدوفية. No obstante, en el TM la traducción habría sido incomprensible sin añadir el arabismo «sufíes».

En NDA no faltan referencias a la religión islámica o a sus instituciones o conceptos. En la Tabla 5 (página siguiente) hemos resaltado algunos ejemplos.

En el primer ejemplo, se usa el arabismo «madrasa» cuya definición en elDRAE es: «Escuela musulmana de estudios superiores», como equi valente de كُنَّاب Lُ كُنَّاب La voz árabe define en el diccionario $A l$-ghan $\imath^{1}$ (en adelante, MGH) comolos lugares en que se imparte la enseñanza primaria y, sobre todo, aquellos en que se enseña El Corán. Se aprecia que no son equivalentes por la diferencia entre el nivel de estudios que se ofrece en cada

Para la transliteración de las palabras árabes seguimos el sistema de Javier Bezos (2005) [http://www.trans.uma.es/ trans_17/Trans17_117-138.pdf]. (Consulta: 1-II-2021). Las palabras transliteradas en las citas de los diccionarios se reproducen tal cual figuran en ellos. 
Tabla 5

\begin{tabular}{|c|c|c|}
\hline NDA & TM & TO \\
\hline 1 & $\begin{array}{l}\text { Ya desde muy pronto rechazó todo intento de aprender } \\
\text { una sola letra del alifato, ya fuera en la madrasa, en la } \\
\text { cofradía religiosa o en casa (20). }\end{array}$ & 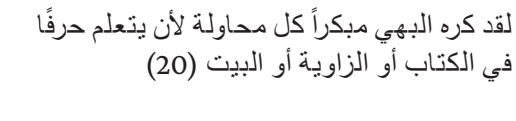 \\
\hline 2 & $\begin{array}{l}\text { ¿Cómo es que ninguno de los dos llegó a ejercer de al- } \\
\text { mocrí? (29) }\end{array}$ & لماذا حقًا لم بستطع أي مذهمـا العمل مقرئا؟ (29) \\
\hline 3 & En el origen eras una hurí (253) & في الأصدل أنت حورية (251) \\
\hline 4 & $\begin{array}{l}\text { Le gustaba pasar el día en la pequeña zagüía de los al- } \\
\text { rededores (26) }\end{array}$ & كان بحب أن بمضي اليور كله في ازاوية)| \\
\hline 5 & Empezó por la azora de la Fe Pura (269) & سورة الإخلاص (304) \\
\hline
\end{tabular}

lugar, debido a la asignación de una acepción particularizada a la palabra árabe general مدرسة al incorporarla en el DRAE.

En LD se evita este arabismo como equivalente de كتاب :No puede saber cómo aprendió el Alcorán [...], si bien recuerda muchos rasgos sueltos de su vida en la escuela alcoránica». (TM: 24) Más adelante en la traducción se limita a "escuela". Y se recurre a la transcripción una sola vez en la contraportada: «la escuela local (kuttab)».

Lo mismo se aprecia en la definición que aporta el DRAE del arabismo «almocrí» (ej.2), pues se especifica que es el lector del Corán en las mezquitas, aunque la voz árabe es general y esta recitación puede llevarse a cabo en varios lugares.

La palabra زاوية (ej. 4), es definida en el MGH como «mezquita sin almimbar, perteneciente sobre todo a una secta sufí y considerada como albergue de los seguidores pobres de esta secta». No obstante, el arabismo «zagüía» usado como equivalente de esta palabra tiene una especificación geográfica en el DRAE: «En Marruecos, especie de ermita en que se halla la tumba de un santón». Es digno de mencionar que el propio trap ductor de NDA evitó este arabismo en otro pasaje de la traducción (véase en la Tabla 5, el ej. núm.1), donde se traduce como «cofradía religiosa».

Por otro lado, la misma palabra زاوية está traducida en el ZB sin recurrir al arabismo correspondiente [TO: «ارية العديان (pág. 83); TM: «el santuario de los Ciegos» (pág. 65)]. Tampoco se usa este arabismo en la traducción de LD en referencia al mismo lugar: «...él se iba a la lección del cheij al-Salihi, en la capilla de los Ciegos» (TM: 91).

En el último ejemplo, la palabra "azora” usada como equivalente de سدورة, es decir, cada uno de los capítulos del Corán, no figura recogida en el DRAE. No obstante, la recoge el Diccionario de uso del español (María Moliner, 1967). Parece que, a pesar de que no esté en el DRAE, este vocablo es frecuentemente usado por los traductores, porque se repite más de una vez en la traducción de NDA y de LD; además, la traductora de ZB lo usa en una nota a pie de página, donde ofrece in- 
Tabla 6

\begin{tabular}{|c|c|c|}
\hline LD & TM & TO \\
\hline 1 & $\begin{array}{l}\text { No le gustaba rezar en la mezquita aljama, porque detes- } \\
\text { taba al imam y a los ulemas que lo rodeaban, y prefería } \\
\text { hacer la oración en cualquier mezquitilla sin ningún re- } \\
\text { lieve ni importancia. (48) }\end{array}$ & 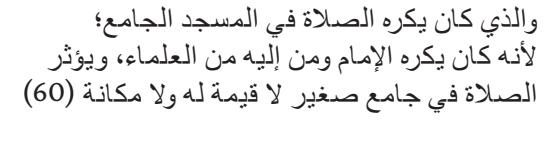 \\
\hline 2 & $\begin{array}{l}\text { El cheij buscó otro alfaquí que venía todos los días a reci- } \\
\text { tarle una azora del Alcorán... (39) }\end{array}$ & 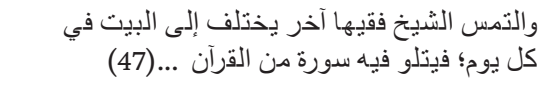 \\
\hline 3 & $\begin{array}{l}\text { Esta vez Dios le inspiró las primeras aleyas de la azora. } \\
\text { (36) }\end{array}$ & ففتح الله عليه بالآيات الأولى من هذه السورة...(44). \\
\hline 4 & $\begin{array}{l}\text { Le gustaba mucho, en efecto, ir a la mezquita, y subir al } \\
\text { alminar y cantar con el almuédano el taslim, que es la } \\
\text { invocación que sigue a la llamada canónica. (36) }\end{array}$ & 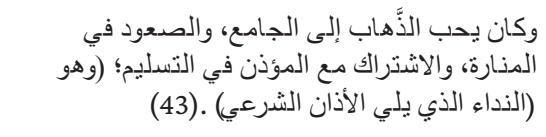 \\
\hline
\end{tabular}

formación sobre el origen de una aleya coránica mencionada en el TO (ZB, pág. 36).

Tal y como vemos en la Tabla 6, en LD abundan los arabismos de este campo semántico.

El arabismo «aljama» está recogido en el DRAE en dos entradas de dos étimos: ğamáah (comunidad) y ğāmi' (mezquita). La yuxtaposición «mezquita aljama» se refiere a la mezquita mayor, donde se reza la oración del viernes, además de las otras oraciones en congregación. En su definición en el DRAE se especifica que es propio de la Edad Media.

Como se ha comentado anteriormente, los arabismos «alfaquí», «imam», «ulema», «aleya», «almuédano» ... son los equivalentes más adecuados para el contexto.

La voz «alminar», según el DRAE, procede del turco a través del francés. No obstante, en el BDELC se señala que su origen se remonta al árabe "'Torre de las mezquitas', princ. s. XIX. Del ár. vg. menâr 'faro', 'alminar', (deriv. de nûr 'fuego'). En el s. XIX se introdujo minarte, tomado del fr. minaret, el cual viene del turco minaré y este del ar. clásico manāra».

\subsubsection{Flora}

Abundan los ejemplos de este tipo de arabismos. Esto se debe a que los árabes trajeron a la península ibérica muchas novedades en este campo, cuyos nombres han enriquecido el léxico español.

Como indicamos en la Tabla 7, en ZB se han encontrado algunos de estos ejemplos.

En la Tabla 8 podemos obervar dos de estas palabras, que también aparecen en la traducción de NDA.

El último arabismo es considerado desusado, según el DRAE. En árabe forma parte de una fra-

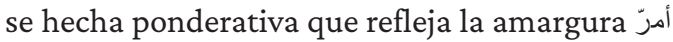

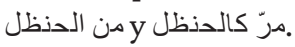

A continuación en la Tabla 9 figuran los ejemplos extraídos de LD.

Estas palabras no son reemplazables por otras, al no existir términos latinos, y son los equivalentes hispánicos de las voces empleadas en el TO.

\subsubsection{Indumentaria}

EnlaépocadelanovelaZB,sinduda,habíaunagran variedad de vestimentas regionales e históricas. 
Tabla 7

\begin{tabular}{|c|c|c|}
\hline ZB & TM & TO \\
\hline 1 & Un jardincito en el que hay arrayán y jazmines (14) & حديقة صغيرة بها ريحان وفل (39) \\
\hline 2 & Se perfume con almizcle (37) & والتعطر بالمسك (59) \\
\hline 3 & $\begin{array}{l}\text { Una mezcla de arrayán con agua de rosas unida a un } \\
\text { soplo de azucena ( } 52)\end{array}$ & السئلاف الريحان بماء الورد المحفوف بروح \\
\hline 4 & $\begin{array}{l}\text { Safadí tenía por costumbre beber infusiones de tama- } \\
\text { rindo, algarrobas (59) }\end{array}$ & من عادات الصدفي شرب التمر هندي والخر \\
\hline 5 & Con ellos compró azúcar y dulce condensado (65) & اندترى سكرًا، وحلاوة معقودة (83) \\
\hline 6 & $\begin{array}{l}\text { Beber una infusión de alholva molida mezclada con } \\
\text { sésamo y leche ( } 88)\end{array}$ & والحليب (108) الحلبة المطحونة المخلوطة بالسمسم \\
\hline
\end{tabular}

Tabla 8

$\begin{array}{lll}\text { NDA TM } & \text { TO }\end{array}$

\begin{tabular}{|c|c|c|}
\hline 1 & Ale, rápido, tráete un zumito de algarroba (59). & هات بسرعة 》سطل《) خروب.(60) \\
\hline 2 & calle del Narciso, del Jazmín, del Arrayán... (274) & شارع الذرجس والفل والريحان ...(271) \\
\hline 3 & $\begin{array}{l}\text { ¿qué es más dulce que la miel y más amargo que el al- } \\
\text { handal? (350) }\end{array}$ & إيش حلى م العسل و إيش مرم الحنظل؟ (347) \\
\hline
\end{tabular}

Tabla 9

\begin{tabular}{|c|c|c|}
\hline LD & TM & то \\
\hline 1 & $\begin{array}{l}\text { [...] y encima todavía un jergón de algodón, ancho y lar- } \\
\text { go... (79) }\end{array}$ & القطن فوق هذا الفراش حشية طويلة عريضة من \\
\hline 2 & [...] y más de una vez cogió hierbabuena y arrayán. (18) & (18). وقُطف له فيها غير مرة نعناعٌ وريحان. \\
\hline 3 & $\begin{array}{l}\text { [...] comprándole pastillas de menta, azúcar cande... } \\
(34)\end{array}$ & الذبات ....... فيشترون له أقراص النعناع 》والسكره" \\
\hline
\end{tabular}


Tabla 10

\begin{tabular}{|c|c|c|}
\hline ZB & TM & TO \\
\hline 1 & $\begin{array}{l}\text { Y que contenía todos los trajes que a uno se le pudie- } \\
\text { ran ocurrir: [...], zaragüelles sirios, chilabas beduinas, } \\
\text { manteletes de los jeques de El Azhar, caftanes, chila- } \\
\text { bas baratas de los vendedores de dulces (69) }\end{array}$ & 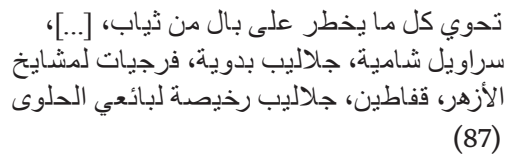 \\
\hline 2 & Eligió una sucia aljuba (69) & انتقى جبة خضراء متسخة (87) \\
\hline
\end{tabular}

Tabla 11

\begin{tabular}{|c|c|c|}
\hline NDA & TM & TO \\
\hline 1 & $\begin{array}{l}\text { Extendiendo sobre él una chilaba que había sacado de } \\
\text { la parte superior del arcón (30) }\end{array}$ & وفرشت على المقعد جلبابًا أخرجته دن أعلى \\
\hline
\end{tabular}

En la Tabla 10, se exponen los siguientes ejemplos sacados de dicha novela.

En el primer ejemplo, el arabismo «zaragüelles» no ha sufrido cambio semántico en el DRAE en lo que respecta a las dos primeras acepciones.

En el MGH, la palabra قفطان (ej. núm. 1) se define como una prenda abierta por delante cuya forma varía de un país a otro. En el DRAE, la voz «caftán» es definida de manera similar: «Vestimenta amplia y larga, sin cuello y con mangas anchas, usada especialmente en los países musulmanes».

En el MGH, se indica que la palabra جلباب es una camisa ancha y larga con mangas y capucha, para hombres y mujeres, y es parte de la indumentaria marroquí. El arabismo «chilaba» se define de manera semejante en el DRAE: «Pieza de vestir con capucha que usan los moros».

La palabra جبة, mencionada en el ejemplo núm. 2, designa, según los diccionarios árabes consultados como el MGH y el $M u^{\prime} \hat{y} a m$ al-lughati al-'arabiyyati al-mu'āsirah (MLAM), una prenda de vestir masculina ancha, abierta por delante, que generalmente se lleva por encima de otra prenda. Esta descripción es bastante distinta a la definición dada a este arabismo en el DRAE:
«Vestidura morisca usada también por los cristianos, consistente en un cuerpo ceñido en la cintura, abotonado, con mangas y con falda que solía llegar hasta las rodillas».

Se observa, pues, que la descripción de algunas de las prendas árabes ha sufrido ciertas modificaciones al ser incorporadas las voces correspondientes en el léxico español.

Por otro lado, resaltamos el ejemplo recogido en la Tabla 11.

A pesar de que casi siempre en la traducción de esta obra (como en pág. 279) se usa el arabismo «chilaba», se ha detectado una vez en la que se la ha transliterado usando la técnica del préstamo en vez del arabismo: «...todos vestidos con galabiyas azules y grises» (NDA, pág. 253).

En la Tabla 12 (página siguiente) podemos ver algunos ejemplos extraídos de LD.

En el primer ejemplo, la voz «chupa» (Del fr. jupe, y este del ár. clás. ğubbah), según el DRAE, tampoco da una idea fiel de lo que es una جبة en árabe (véase el comentario sobre el arabismo 'aljuba' en el ej. núm. 2 de ZB), sobre todo la que llevan los ulemas azharistas, pues se define en el DRAE como 'chaqueta', 'cazadora' o 'prenda de 
vestir masculina que cubría el tronco, con faldillas de cintura para abajo y mangas ajustadas, que se llevaba generalmente debajo de la casaca'.

\subsubsection{Vida socialy utensilios}

Esta categoría es más o menos miscelánea, pues acoge ejemplos que reflejan aspectos de la vida social, utensilios usados en el día a día, las divisiones de los hogares, herramientas agrícolas, cosméticos, instrumentos musicales, etc.

A continuación, en la Tabla 13, recogemos los siguientes ejemplos de la traducción del ZB.

La palabra ساقية, de la que proviene el arabismo «acequia», tiene dos significados en el MGH, pues puede referirse a un canal que sirve para

Tabla 12

\begin{tabular}{|c|c|c|}
\hline LD & TM & TO \\
\hline 1 & $\begin{array}{l}\text { Previamente le habían comprado para ese día un caftán } \\
\text { nuevo, una chupa nueva, un tarbús nuevo y unas babu- } \\
\text { chas nuevas. ( } 41 \text { ) }\end{array}$ & 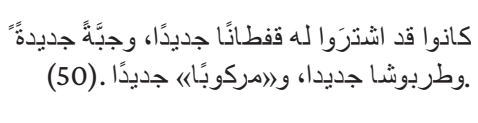 \\
\hline 2 & $\begin{array}{l}\text { Lo que llevaban en sus alforjas eran, en efecto, milagros } \\
\text { de santones, historias de conquistas y de algaras... (54) }\end{array}$ & 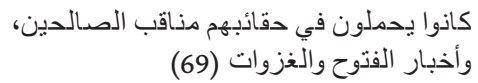 \\
\hline
\end{tabular}

Tabla 13

\begin{tabular}{|c|c|c|}
\hline ZB & TM & то \\
\hline 1 & ...elevando el agua desde el canal a las acequias (129) & رفع الماء من الترعة إلى القنوات(148). \\
\hline 2 & Crujían las ruedas de la noria (39) & تصر عجلات الساقية (60). \\
\hline 3 & Cubierto por los restos de una alfombra (51) & مغطاة ببقايا سجادة (71). \\
\hline 4 & $\begin{array}{l}\text { Transportando productos del Alto Egipto, además de cán- } \\
\text { taros y jarras (183) }\end{array}$ & و تلازل له المدصدول من الصعيد، غير القلل \\
\hline 5 & $\begin{array}{l}\text { Era un cuarto oscuro que se iluminaba día y noche con un } \\
\text { candil (183) }\end{array}$ & حجرة مظلمة تضداء بقنديل ليلًا ونهارًا (199). \\
\hline 6 & $\begin{array}{l}\text { Las cantantes salieron a recibirlo bailando [...]. Se oyeron } \\
\text { albórbolas de las ventanas (71) }\end{array}$ & 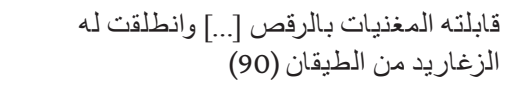 \\
\hline 7 & $\begin{array}{l}\text { Y contemplaba los suaves almohadones que le habían } \\
\text { protegido a ella el cuerpo de la dureza de la pared (82) }\end{array}$ & 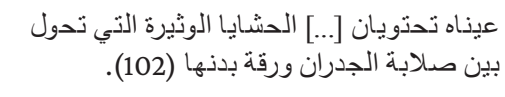 \\
\hline 8 & $\begin{array}{l}\text { Le pidió que preparara una historia para ser cantada } \\
\text { acompañada del rabel (99) }\end{array}$ & طلب مذه إعداد حكاية تروى على الربابة (119). \\
\hline
\end{tabular}


236 conducir el agua para regar y a la rueda de agua o noria. No obstante, la acepción dada al arabismo «acequia» en el DRAE se limita al primer significado solamente, el de canal, que es lo que se menciona en el TO en el ejemplo núm. 1. Es digno de mencionar que se ha verbalizado esta palabra de origen árabe creando el verbo «acequiar», que significa 'hacer acequias'.

El arabismo «albórbolas» (ej. 6) es un buen ejemplo delos cambios semánticos que afectaron a algunas de las voces árabes aceptadas en el español. Según el DRAE, esta palabra proviene del étimo árabe walwalah (ولولة) que es un grito repetido de lamento por una desgracia. Por el contrario, en la definición de esta palabra en español se especifica que este grito demuestra alegría especialmente. Con este sentido nuevo, sería el equivalente aceptado de la voz árabe jel TO, que se define en el MLAM como un sonido especial que en las ocasiones felices emiten las mujeres haciendo vibrar la lengua rápidamente dentro de la boca.

En la Tabla 14 ofrecemos los ejemplos extraídos de la traducción de NDA.

En el ejemplo núm. 2, se observa que el arabismo «kohol» está escrito en cursiva, como se

Tabla 14

\begin{tabular}{|c|c|c|}
\hline NDA & TM & TO \\
\hline 1 & $\begin{array}{l}\text { Las piastras, los céntimos..., las puso en un pequeño } \\
\text { adufe que llevaba en la mano (112) }\end{array}$ & 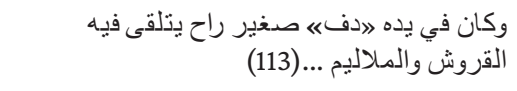 \\
\hline 2 & $\begin{array}{l}\text { Zahra no pudo evitar que las lágrimas le corrieran por } \\
\text { las mejillas mezclándose con el negro del kohol (280) }\end{array}$ & 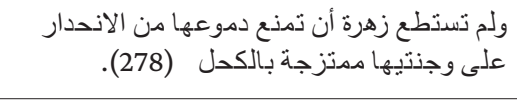 \\
\hline 3 & $\begin{array}{l}\text { al estar suelo sin adoquinar y tapizado de pequeños } \\
\text { guijarros blancos ( } 43 \text { ) } \\
\text { ya preparado para su inmediato adoquinado }(54)\end{array}$ & 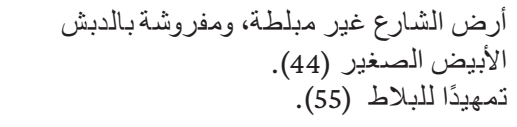 \\
\hline 4 & Con un candil de aceite en una mano (51) & ترفع في يدها لمبة سهاري (52). \\
\hline 5 & $\begin{array}{l}\text { Compraremos algodón y tela para tapizar y mañana } \\
\text { tendrás todo un ajuar }(60)\end{array}$ & 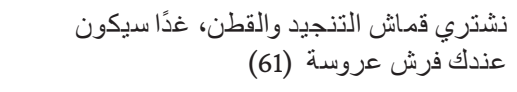 \\
\hline 6 & $\begin{array}{l}\text { Muchas eran viejas con el pelo blanco, suelto y teñido } \\
\text { de alheña (56) }\end{array}$ & والمديّى مذهن (57) عجائز، تركن شعرهن الأبيض \\
\hline 7 & $\begin{array}{l}\text { La pequeña Chaukiya se entretenía yendo y viniendo de } \\
\text { un cuarto a otro a través del zaguán (151) }\end{array}$ & كانت الطفلة شوقية تروح وتجيء لاهية في \\
\hline 8 & $\begin{array}{l}\text { Mientras que la apacible Ivone se retiró del alféizar } \\
\text { (151). }\end{array}$ & تراجعت إيفون الهادئة عن إفريز الشباك (151). \\
\hline 9 & $\begin{array}{l}\text {...esos olores para él tan queridos: el del adobe de los } \\
\text { muros recocidos por la canícula (17) }\end{array}$ & 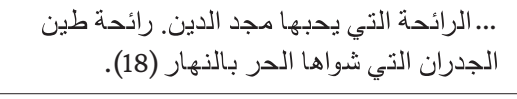 \\
\hline 10 & Sus pasos lo condujeron a la azotea (17). & ووجد مجد الدين نفسه بصعد أعلى السطح (18). \\
\hline
\end{tabular}


Tabla 15

\begin{tabular}{|c|c|c|}
\hline LD & TM & Tо \\
\hline 1 & $\begin{array}{l}\text { Los panderos, las albórbolas y el canto le recordaron, } \\
\text { en efecto, el campo natal. (118) }\end{array}$ & الغناء (154) ريفه بهذه الطبول وهذه الزغاريد وهذا \\
\hline 2 & $\begin{array}{l}\text { La alegría y el alborozo danzaban en torno al dolor y al } \\
\text { sufrimiento... (119) }\end{array}$ & والعذاب (155) والفرح والابتهاج يرقصدان من حول الألم \\
\hline 3 & $\begin{array}{l}{[. . .] \text { las habas, las albóndigas picantes y los puerros... }} \\
(152)\end{array}$ & الفول والطعمية والكراث ...(195) \\
\hline 4 & $\begin{array}{l}\text { Consumada esta hazaña, eran de oír los gritos, y las } \\
\text { canciones, y la algazara, el bullicio... (16) }\end{array}$ & 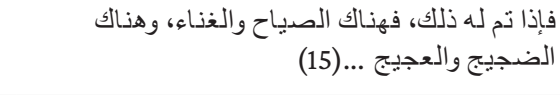 \\
\hline 5 & $\begin{array}{l}{[\ldots] \text { y entre ellas dos cajoncitos ocultos, en los que la }} \\
\text { madre guardaba sus alhajas, cuando las tenía. (122) }\end{array}$ & 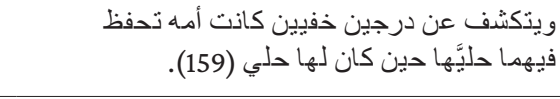 \\
\hline 6 & $\begin{array}{l}\text { se vio nombrado pensionista con dos panes al día [...] y, } \\
\text { además, con una alacena en el pórtico... (151) }\end{array}$ & 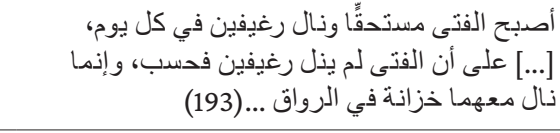 \\
\hline 7 & $\begin{array}{l}\text { Allí encontraba una estera tendida por tierra, sobre la } \\
\text { cual había una alfombra vieja, pero todavía en buen } \\
\text { estado. Sobre ella se sentaba el niño durante el día y } \\
\text { en ella dormía por la noche, con una almohada que le } \\
\text { daban (79) }\end{array}$ & 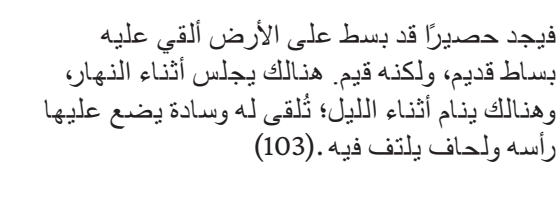 \\
\hline 8 & $\begin{array}{l}\text { El cheijy su mujer recorrían el ancho zaguán destecha- } \\
\text { do llamando a su hijo (66) }\end{array}$ & 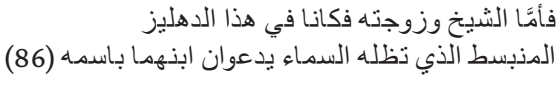 \\
\hline
\end{tabular}

escriben los vocablos extranjeros, aunque esta palabra figura en el DRAE con esta grafía y con la variante «kohl» también.

El ejemplo núm. 3 muestra cómo se produce la derivación de los vocablos árabes para crear más palabras. El verbo «adoquinar» y el participio pasivo sustantivado «adoquinado» se derivan ambos del arabismo «adoquín». De la misma manera, el arabismo «alheña» (ej. 6) ha dado lugar al verbo «alheñar» cuyo participio habría sido adecuado usarlo en el TM también como alternativa de «teñido de alheña».
Es interesante que algunos de los étimos que dieron lugar a arabismos en español ya no se usen en el árabe escrito con mucha frecuencia. Un ejemplo de ello es la palabra شُوار, de la que proviene el arabismo «ajuar» ${ }^{2}$.

En la Tabla 15, contamos con algunos ejemplos en LD.

2 Para formular tal observación, se ha consultado: REAL ACADEMIA ESPAÑOLA: Banco de datos (CORPES XXI) [en línea]. Corpus del Español del Siglo XXI (CORPES). <http:// www.rae.es $>$. [18-8-2020] y <http://arabicorpus.byu.edu/>. 
238 De la misma manera que cambió el significado del arabismo «albórbola» de su étimo, la voz «alborozo» ('1. m. Extraordinario regocijo o alegría.', DRAE) guarda nula relación con su étimo según el DRAE (Del ár. hisp. alburúz, y este del ár. clás. burūz 'parada militar previa a una expedición'). No obstante, en el BDELC se ofrece una explicación: «Del ar. Burûz 'salir en gran pompa a recibir a alguno', infinitivo del verbo báraz; por los gritos de alegría que se daban entonces».

El arabismo «albóndiga» se refiere generalmente, según el DRAE, a las bolas de carne o pescado picado, mientras que la comida egipcia popular طعمية se prepara de habas, un ingrediente económico.

En el ejemplo núm. 4, الضجيج والعجيج es una colocación basada en el uso de parónimos de significado semejante. Habría sonado más natural en castellano traducirla con una sola palabra, para evitar la repetición. No obstante, este calco dio lugar al uso de un arabismo más: «algazara», que en este contexto coincide con la primera acepción recogida por el DRAE: «Ruido, gritería de una o de muchas personas juntas, que por lo común nace de alegría».
En el ej. 5, se ha preferido el arabismo «alhaja» a la alternativa «joya»; y en el siguiente ejemplo, el arabismo «alacena», a «armario», mientras que los arabismos «alfombra» $\mathrm{y}$ «almohada» son los equivalentes acuñados de las voces árabes del TO.

\subsection{Arabismos con voces alternativas más conocidas y usadas}

Como ya se dijo, los arabismos a veces pueden ser las únicas voces equivalentes aceptadas de una voz árabe y así los referentes no tienen más que este arabismo para designarlos, como se ha visto en muchos de los ejemplos mencionados más arriba. Sin embargo, otras veces se usan las palabras de origen árabe deliberadamente en las traducciones del árabe al español para crear un ambiente exótico o para recrear el entorno en el que se desarrollan los acontecimientos de la obra original, además de para dar nueva vida a arabismos caídos en desuso.

En la Tabla 16 podemos ver los siguientes ejemplos extraídos de ZB.

Tabla 16

\begin{tabular}{|c|c|c|c|}
\hline ZB & TM & TO & ALTERNATIVA \\
\hline 1 & $\begin{array}{l}\text { donde todo lugar, pueblo, con- } \\
\text { centración o alquería, cada tro- } \\
\text { zo de la tierra de Egipto... (44) }\end{array}$ & لكي بر مصدة قدم، كل قرية، أي كوم أو عزبة، أي إقطاع & finca \\
\hline 2 & $\begin{array}{l}\text { Y habían hecho sonar los ataba- } \\
\text { les un tiempo más prolongado } \\
\text { que el habitual (59). }\end{array}$ & دقوا الطبلخاناة وقتًا أطول من المعناد (78) & Timbal, tambor \\
\hline 3 & Entró en la alcoba de Salima (26) & عندما دخل إلى حجرة سالمة (49) & Dormitorio \\
\hline 4 & Alguien de la gente de zoco (86) & أحد العامة من السوق (106). & Mercado \\
\hline 5 & $\begin{array}{l}\text { Supe por mi trujamán Alí que la } \\
\text { comitiva había salido (147) }\end{array}$ & عرفت دن علي مثرجمي أن الموكب خرج فعلا (165) & Intérprete \\
\hline
\end{tabular}


Tabla 17

\begin{tabular}{|c|c|c|c|}
\hline NDA & TM & TO & ALTERNATIVA \\
\hline 1 & $\begin{array}{l}\text { Magdeddín contempló cómo una ne- } \\
\text { gra jaima acababa de plantarse sobre } \\
\text { el mundo (41). }\end{array}$ & 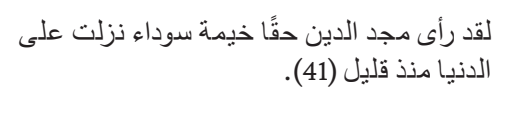 & Tienda \\
\hline 2 & $\begin{array}{l}\text { Se habría quedado a solas a la luz de } \\
\text { un candil y se dispondría a leer el Co- } \\
\text { rán, en la alcoba (31). }\end{array}$ & 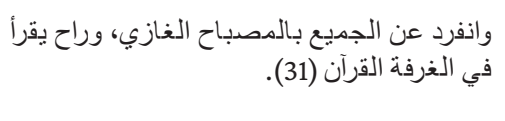 & Dormitorio \\
\hline 3 & $\begin{array}{l}\text { Empezó a deambular por los zocos } \\
\text { de las aldeas vecinas ( } 45)\end{array}$ & راح يتسكع في أسواق القرى المجاورة (45) & Mercados \\
\hline
\end{tabular}

Tabla 18

\begin{tabular}{|c|c|c|}
\hline LD & TM & то \\
\hline 1 & $\begin{array}{l}\text { Esta segunda servía, a la vez, de alcoba, de comedor, de } \\
\text { sala, de tertulia nocturna y de cuarto de estudio (78) }\end{array}$ & و وغرفي على ذلكديث، وغرفة الذوم، وغرفة والسمر، وغرفة الطعام، \\
\hline
\end{tabular}

En la tabla 17 indicamos los ejemplos que hemos encontrado en la traducción de NDA.

En la Tabla 18, mostramos este ejemplo de arabismo reemplazable hallado en LD.

\subsection{Arabismos de uso problemático}

Hay algunos arabismos cuyo uso es problemático en la traducción por la diferencia existente entre las acepciones que tiene la voz en el DRAE y los significados originales que dichas voces tienen en los diccionarios árabes. De estos arabismos destaca la palabra «jeque» o شيخ, que a menudo se menciona en las obras árabes traducidas.

El problema es que en el DRAE esta palabra se define: «Del ár. hisp. šáyh y este del ár. clás. šayh “anciano que manda”. 1. m. Entre los musulmanes y otros pueblos orientales, superior o régulo que gobierna y manda un territorio o provincia, ya sea como soberano, ya como feudatario». No obstante, en el árabe es una palabra polisémica. En Ar-rā'id: mu'ŷam lughawī 'așrī (RMLA) se indica que puede referirse al que ha alcanzado la vejez; al hombre de religión para los musulmanes; al soberano de un pueblo; y por extensión a todo hombre de rango elevado, entre otros sentidos.

A la incongruencia entre los significados de la voz árabe y el arabismo se añade el hecho de que, para algunos traductores, este término español «había adquirido en los últimos tiempos connotaciones negativas, a causa de los excesos de algunos jeques del Golfo». (Fernández Parrilla, 1997: 462)

En la traducción de ZB, se observa que se ha recurrido al arabismo «jeque» aunque su definición en español no aporte el significado de «hombre de religión», que es el significado intencionado en el TO, (ver Tabla 19, en página siguiente). 
Tabla 19

\begin{tabular}{|c|c|c|}
\hline ZB & TM & то \\
\hline 1 & El agua y el mensaje, jeque Amru (62) & المغطس.. والمكبساتي يا شيخ عمرو (81) \\
\hline 2 & Tenía que subir donde su maestro el jeque Abú Saúd (30) & "لاببد من طلوعه إلى مولاه الثيخ "أبو السعود (52). \\
\hline 3 & manteletes de los jeques de El Azhar (69) & فرجيات لمشايخ الأزهر (87) \\
\hline
\end{tabular}

Tabla 20

\begin{tabular}{|c|c|c|}
\hline ZB & TM & TO \\
\hline 1 & $\begin{array}{l}\text { Ha enviado mensajes por todo Egipto convocando a la } \\
\text { guerra a los jeques beduinos (20) }\end{array}$ & العربان (44) الأنباع إلى بلاد مصر بستذفر مشايخ \\
\hline
\end{tabular}

Tabla 21

\begin{tabular}{llr}
\hline NDA & \multicolumn{1}{c}{ TM } \\
\hline 1 & $\begin{array}{l}\text { Cheij Magd, tú eres un buen hombre, pero solo ves el } \\
\text { mundo a través del Corán. (19) }\end{array}$ & TO \\
\hline
\end{tabular}

Tabla 22

\begin{tabular}{|c|c|c|}
\hline NDA & TM & TO \\
\hline 1 & el anciano más venerable del pueblo (17) & شيخ البلد (18) \\
\hline 2 & al cheij más respetado de su clan (302) & شديخ القبيلة (298) \\
\hline 3 & jefe de la guardia (26) & شيخ الذفراء (26) \\
\hline
\end{tabular}

También en la misma obra, مشايخ se usa como equivalente de jefe o soberano de un grupo de gente como se muestra en la Tabla 20.

No obstante, en la traducción de NDA, se ha evitado el uso de este arabismo en la traducción del trato, muy repetido, del protagonista, que se le da por ser hombre de religión y por haber memorizado el Corán, y se ha recurrido al préstamo cheij (ver Tabla 21).

El traductor de esta obra ha señalado en otra ocasión que a veces los arabismos pueden ser falsos amigos en la traducción, pues dice: «A veces, la existencia de arabismos en español es de gran utilidad para el traductor. Sin embargo, tengamos presente que las equivalencias no son siempre directas». (García Suárez y Pérez Cañada, 2017: 29)

En efecto, como vemos en la Tabla 22, se ha evitado el arabismo también cada vez que se menciona la palabra شيخ usada con el sentido de 'jefe de un grupo de gente', aunque coincida con la definición de la palabra «jeque» en el DRAE. 
Tabla 23
LD
TM To

1

El jeque le preguntó: “¿No dices que es descendiente del Profeta por el lado de al-Hasan ibn 'Alí?” (52)

فقال له الثيخ: ألست تزعم أنها شريفة من نسل

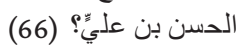

Al terminar la peregrinación, cuando se encaminaban a

فلما فرغوا من الحج وانصدرفوا إلى المدينة،

2 Medina, la vieja, en el camino, se cayó de su cabalgadu-

ra... (52)

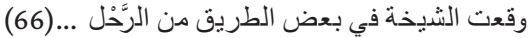

El cheij seguía recitando su Alcorán, y la madre implorando la asistencia divina (64)

فيستطيع الشيخ أن يتلو القرآن، وتستطيع هذه

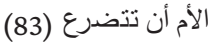

Por último, en la Tabla 23, en el TO de LD se usa شيخ, en la mayoría de los casos, para referirse a 'hombres de religión'. En la traducción se usa el arabismo «jeque» y el préstamo cheij indistintamente, aunque el uso de esta última voz es mucho más que el del arabismo. Hemos observado que el arabismo «jeque» fue usado solo en el principio de la traducción y luego fue reemplazado por cheij (y su plural cheijs) hasta el final de la traducción sin criterio claro.

Se observa que, en el segundo ejemplo, شيخة se refiere a una mujer de tercera edad, por eso el traductor utilizó el equivalente «vieja».

\section{CONCLUSIONES}

A través de este estudio, ha sido posible deducir las siguientes funciones que cumplen los arabismos usados como equivalentes en esta muestra de traducciones literarias del árabe al español:

I. Llenar un vacío cultural en el caso de los culturemas, evitando recurrir a la técnica del equivalente cultural o la adaptación a la cultura meta.

2. Suplir la inexistencia de otras voces equivalentes en español, por ejemplo, de origen latino. Es decir, porque el arabismo es la única palabra que designa el objeto y es bastante usada, como almohada y azúcar, o porque la otra alternativa, si la hay, es el nombre científico latino, como en el caso de los nombres de flores y similares.

3. Ambientar el texto y exotizarlo, dotándolo de un matiz de antigüedad o arabizante, dependiendo de la época en la que se desarrollan los acontecimientos de la novela y el entorno en que se inscriben, así como el efecto que se desea dar al texto final.

\section{Reflejar una posible tendencia ideológica} que se traduce en la búsqueda de arabismos para darles nueva vida, aunque sus significados hayan cambiado, no sean totalmente adecuados al contexto o se trate de voces que han caído en desuso.

Además, hemos podido observar que la actitud de los traductores no es uniforme en cuanto a la traducción de algunas palabras comu-

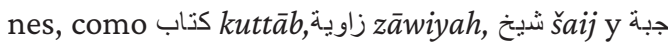
yubbah.

Por otro lado, se ha concluido que los arabismos que han llegado a tener en el léxico español un significado distinto al de sus étimos no representan inconveniencia a la hora de ser usados en la traducción, a condición de que su nuevo sig- 
242 nificado corresponda con el significado intencionado en el TO, como el arabismo «albórbola». El asunto es diferente si hay en su definición una especificación que no concuerda con lo expresado en el TO, como en el caso del arabismo «madrasa», porque el lector del TM podría confundirse si consulta el diccionario español para averiguar un arabismo que desconoce $\mathrm{u}$ otro.

Finalmente, a veces los arabismos son equivalentes obvios pero sólo aparentes, su uso resulta algo forzado en el ambiente general de la novela, o han sufrido derivas semánticas que oscilan entre leves a drásticas en el diccionario de español, aunque todavía mantengan semejanza fónica o grafémica con su étimo, como los arabismos «almocadén», «jeque» o «jalifa». Además, la temática y la época en la que transcurre la acción de una novela son elementos decisivos a la hora de elegir equivalentes para los elementos culturales y es indispensable estudiar si el recurso a un arabismo desusado es adecuado en la traducción o, por el contrario, genera ambigüedad.

\section{REFERENCIAS BIBLIOGRÁFICAS}

Abdel Meguid, Ibrahim (2000 [1996]): Lā ahad yanām fī l-Iskandariyya [Nadie duerme en Alejandría], Köln (Alemania): Manšūrāt al-Ğamal.

Abdel Meguid, Ibrahim (2016): Nadie duerme en Alejandría, trad. Pablo García Suárez, Madrid: Ediciones del Oriente y del Mediterráneo.

Corriente, Federico (2004): «Los arabismos del léxico hispánico primitivo», Revista de Filología Española, lxxxiv, 67-93. Disponible en <http://xn--revistadefilologiaespaola-uoc.revistas.csic.es/index.php/rfe/ article/view/98/97>. [Consulta: 24- II-2021].

El Guitani, Gamal (2017 [1974]): Al-Zayn̄̄ Barakāt, Guiza: Dār Nahḍat Miṣr.

El Guitani, Gamal (1994): Zaini Barakat, trad. Milagros Nuin, Madrid: Ediciones Libertarias, Al-Kálima (novela).

EMBAREK, Malika (1997): «El retorno de las palabras exiliadas», en Esther Morillas y Juan Pablo Arias (eds.): El papel del traductor, Salamanca: Colegio de España, 469-476.

EMBAREK, Malika (2000), «Mis arabismos preferidos: almacabra», El Trujamán, disponible en <https:// cvc.cervantes.es/trujaman/anteriores/febrero_00/24022000.htm>, (consulta: 8-II-2021).

Fernández Parrilla, Gonzalo (1997): «Jaque al jeque o de la traducción y la edición de literatura árabe contemporánea en español», en Esther Morillas y Juan Pablo Arias (eds.): El papel del traductor, Salamanca: Colegio de España, 461-468.

Fernández Parrilla, Gonzalo y Manuel Feria García (coords.) (2000): Orientalismo, exotismo y traducción, Toledo: Ediciones de la Universidad de Castilla-La Mancha.

García SuÁrez, Pablo y Luis M. Pérez Cañada (2017): Manual de traducción periodística árabe-español. Introducción teórica, textos y claves. Cuadernos de la Escuela de Traductores de Toledo, núm. 17, Universidad de Castilla-La Mancha. Recuperado de $<$ https://issuu.com/escueladetraductorestoledo/ docs/cuaderno_17>. [Consulta: 17-VIII-2020].

GIL-BARDAJí, Anna (2016): «La traducción del árabe en España: panorámica histórica», Quaderns. Revista de Traducción, 23, 59-78. Recuperado de <https://ddd. uab.cat/pub/quaderns/quaderns_a2016n23/quaderns_a2016n23p59.pdf >. [Consulta: 15-II-2021].

Gutiérrez Almenara, Angelina (2016): Los traductores de árabe hablan: El caso de Ediciones del Oriente y del Mediterráneo (1994-2016), Cuadernos de la Escuela de Traductores de Toledo, núm. 15, Universidad de Castilla-La Mancha.

Husein, Taha (2014[1929]): Al-ayyām, El Cairo: Hindawi Foundation for Education and Culture.

Husein, Taha (2017[1954]), Los días: Memorias de infancia y juventud. Trad. Emilio García Gómez, Editor digital: Titivillus.

IBN 'ABdillāH Al-Maghlūt, Sāmī (2013): Ațlas tārīh al'așr al-mamlūkī (Atlas de la historia de la época de los mamelucos), Riad: Obekan.

Millar C., María Angélica (1998): «Los arabismos en la lengua española», BFUCh xxxvII (1998-1999): 781-801. Recuperado de: <http://repositorio.uchile.cl/bitstream/handle/2250/134131/Los-arabismos-en-la-lengua-espanola.pdf? sequence $=1>$. [Consulta: 17-VIII-2020]. 
NewMARK, Peter (1999 [1988]): Manual de traducción, versión española de Virgilio Moya, 2.a ed., Madrid: Cátedra (lingüística).

PEÑA, Salvador (ed.) (2009): Materia de trujamanes, Cuadernos de la Escuela de Traductores de Toledo, núm. 10, Universidad de Castilla-La Mancha.

Rubiera Mata, Ma Jesús (2004): «La traducción de la literatura árabe clásica», en Míkel de Epalza (coord.) y otros, Traducir del árabe, Barcelona: Editorial Gedisa.

SÁENZ, Miguel (2009): «Traducción y cultura en el ámbito literario», Entreculturas núm 1., 763-771.

VenutI, Lawrence (1995): The Translator's Invisibility. A History of Translation, London\& New York: Routledge.

\section{Diccionarios y corpus en Línea}

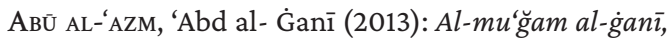
$<$ https://www.almaany.com/>.

Al-FAYRUZĀBĀDī, Mağd al-Dīn Abū Ṭāhir Muhammad ibn Ya'qūb, Al-qamūs al-muhīt [El Diccionario Global], consultado en <https://www.almaany.com/>.

Anónimo (2005): Diccionario de la lengua española, Espasa-Calpe <https://www.wordreference.com/>.

Corominas, Joan (1987 [1961]): Breve diccionario etimológico de la lengua castellana, 3.a edición, Madrid: Gredos.

Corriente, Federico (1997): A Dictionary of Andalusi Arabic, Brill, Leiden.

Corriente, Federico (2008): Dictionary of Arabic and Allied Loanwords, Spanish, Portuguese, Catalan, Galician and Kindred Dialects, Leiden: Brill

Instituto De Investigación Rafael LAPESA DE LA ReAL Academia Española (2013): Mapa de diccionarios [en línea]. < http://web.frl.es/ntllet>. [17- VIII-2020]

Moliner, María (1967): Diccionario de uso del español, Madrid: Gredos, 3.0 (CD-ROM).

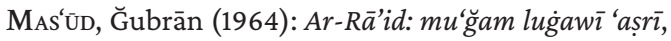
$<$ https://www.almaany.com/>.

MuḥTĀr 'UMAR, Aḥmad (2008): Mu'ğam al-lugia al-'arabiyya al-mu'āṣirah [Diccionario de la lengua árabe contemporánea], en <https://www.almaany.com/>.
PARKINSON, Dilworth B. (2012), arabiCorpus, disponible en $<$ http://arabicorpus.byu.edu/>.

REAL ACADEMIA ESPAÑola (2014): Diccionario de la lengua española (23a ed.). Consultado en <http:// www.rae.es/rae.html>.

REAL ACADEMIA ESPAÑOLA (2020): Banco de datos (CORPES XXI) [en línea]. Corpus del Español del Siglo XXI (CORPES) <http://www.rae.es> [18-vIII-2020]. 